\title{
Mir-509-5p joins the Mdm2/p53 feedback loop and regulates cancer cell growth
}

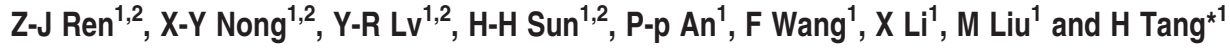

Although the Mdm2/p53 interaction has been well documented, it is not clear whether there are new microRNAs participating in this regulatory network. Here, we provide evidence that miR-509-5p, which is downregulated in a subset of newly diagnosed cervical cancer and hepatocellular carcinoma tissues compared with the adjacent nontumor tissue, can be activated by p53 through binding the promoter of miR-509-5p and it suppresses the growth and invasion/migration of cervical cancer and hepatoma cells by regulating apoptosis and the G1/S-phase transition of cell cycle. Furthermore, Mdm2 was identified to be a target of miR-509-5p by targeting its $3^{\prime}-$ UTR. Restoration of Mdm2 abrogated the cell phenotypes induced by miR-509-5p. Moreover, ectopic expression of miR-509-5p in HeLa and QGY-7703 cells repressed the expression of Mdm2, subsequently enhancing its p53-activating effects. These results suggest that miR-509-5p is a new regulator of Mdm2/p53 pathway and may play a key role in cancer development.

Cell Death and Disease (2014) 5, e1387; doi:10.1038/cddis.2014.327; published online 21 August 2014

MiRNAs are small, endogenous, noncoding RNAs that have been shown to be crucial post-transcriptional regulators of gene expression. MiRNAs typically silence multiple genes instead of a single gene, as miRNAs target the $3^{\prime}$-untranslated regions $\left(3^{\prime}-U T R\right)$ of mRNAs by partial sequence homology, leading to mRNA degradation or translation repression. ${ }^{1}$ It is predicted that an average miRNA can target hundreds of mRNAs. Evidence suggests that miRNAs are often deregulated in human malignancies and can function as either oncogenes or tumor suppressors in a subset of cancers, ${ }^{2}$ such as B-cell chronic lymphocytic leukemia, ${ }^{3}$ breast cancer, ${ }^{4}$ lung cancer, ${ }^{5}$ hepatocellular carcinoma ${ }^{6}$ and gastric adenocarcinoma. ${ }^{7}$ Despite the overwhelming evidences suggesting that miRNAs could play a causal role in human malignancies, the mechanisms underlying the deregulation of miRNAs and miRNA-mediated gene silencing that leads to cancer development are still poorly understood. It has been found that miRNA expression is regulated by many factors, such as MyoD, Mef2, ${ }^{8}$ TGF $-\beta^{9}$ and p53. It has also been shown that the miR-34 family is induced by the tumor suppressor p53 and elicits p53-like responses, such as senescence, cell cycle arrest and apoptosis, depending on the cell type. ${ }^{10}$

The tumor suppressor p53 is a master regulator controlling diverse cellular pathways by either activating or repressing downstream genes, such as S100A2 and TP53AP1. ${ }^{11}$ Studies identified that $\mathrm{p} 53$ can be regulated by other proteins, such as HIPK2, ${ }^{12}$ HDAC, ${ }^{13}$ p14ARF, Mdm2, Cop-1 and Pirh$2{ }^{14}$ Among them, murine double minute 2 (Mdm2), an E3 ubiquitin ligase, has been well documented. Mdm2, which is overexpressed in many human tumors, can mediate p53 ubiquitination for proteasomal degradation, resulting in a decreased level of p53 in the cells. ${ }^{15-17}$ Thus, p53 can be antagonized by Mdm2 that offers a therapeutic strategy. ${ }^{18}$

Recent studies found that miRNAs are involved in the Mdm2/p53 pathway; ${ }^{19,20}$ for example, miR-605 can impair the Mdm2/p53 feedback loop. ${ }^{21}$ The goal of this study was to determine whether there are new miRNAs that participate in the Mdm2/p53 pathway. Using microarray analysis, we identified that miR-509-5p was significantly upregulated by p53. We further showed p53 induced the expression of miR-509-5p by interacting with miR-509-5p promoter. Ectopic expression of miR-509-5p inhibited cervical cancer and hepatocellular carcinoma cell proliferation and invasion. Furthermore, Mdm2 can be directly targeted and downregulated by miR-509-5p, and this resulted in the increase of the p53 protein level that subsequently repressed the cell cycle and induced apoptosis. These results suggest that, as a new member of the $\mathrm{p} 53$ regulatory network, miR-509-5p provides a direct link between Mdm2 and p53 in the regulatory network.

\section{Results}

Regulation of miR-509-5p after induction of p53. To determine the miRNAs that are regulated by $\mathrm{p} 53$, miRNA microarray analysis was used to examine the alterations in miRNA expression after overexpression of p53 in HeLa cells. The results showed that there were 19 differently expressed miRNAs, including 10 upregulated or 9 downregulated miRNAs (Figure 1a). We further confirmed the expression of these miRNAs by quantitative reverse transcription-PCR (qRT-PCR; Supplementary Figure S1). The results indicated that these miRNAs may be involved in cancer cell

\footnotetext{
${ }^{1}$ Tianjin Life Science Research Center and Department of Microbiology, School of Basic Medical Sciences, Tianjin Medical University, Tianjin, China

${ }^{*}$ Corresponding author: H Tang, Tianjin Life Science Research Center, Department of Microbiology, Tianjin Medical University, 22 Qi-Xiang-Tai Road, Tianjin 300070, China. Tel/Fax: + 8622 23542503; E-mail: htang2002@yahoo.com

${ }^{2}$ These authors contributed equally to this work.

Abbreviations: ASO, antisense methyoxy-modified nucleic acid oligo; ChIP, chromatin immunoprecipitation; CLL, chronic lymphocytic leukemia; FBS, fetal bovine serum; GAPDH, glyceraldehyde-3-phosphate dehydrogenase; HCC, hepatocellular carcinoma; Mdm2, murine double minute 2; PI, propidium iodide; P/S, penicillin/ streptomycin; p53REs, p53 response elements; $3^{\prime}$-UTR, 3'-untranslated region

Received 19.5.14; revised 29.6.14; accepted 01.7.14; Edited by G Raschellà
} 
development. Because p53 primarily acts to activate the transcription of tumor suppressive genes, we analyzed the miRNAs that were upregulated following p53 overexpression. Among these differential miRNAs, miR-509-5p was the most prominently upregulated.

Inspection of the putative miR-509-5p promoter using MatInspector module of the Genomatix software suite (Bayerstr, Germany) further suggested that p53 is a potential miR-509-5p regulator, because we identified two candidate p53-binding sites within a 800-bp DNA fragment upstream to the pre-miR-509-5p. Therefore, we examined whether endogenous p53 promotes the expression of miR-509-5p in cervical cancer (HeLa and Caski) and hepatocellular carcinoma (HCC) cell lines (QGY-7703 and HepG2). The tumor suppressor p53 can be activated by genotoxic stress, such as doxorubicin (doxo) or serum starvation. QRT-PCR and western blot analysis showed that p53 expression was significantly upregulated in cells treated with doxo or serum starvation (Figures $1 \mathrm{~b}$ and $\mathrm{c}$, left panel; Figure 1e and $\mathrm{f}$, top panel). We further confirmed the qRT-PCR result of p53 expression in four cell lines treated with 0.5 or $1.0 \mu \mathrm{g} / \mathrm{ml}$ doxo by another two primers (Supplementary Figure S2). Given that p21 is the downstream target of $p 53,{ }^{22}$ we also examined p21 protein level and found the expression of p21 was increased when $\mathrm{p} 53$ was induced by doxo or serum starvation (Figure 1e and f, bottom panel). Accordingly, we observed that a
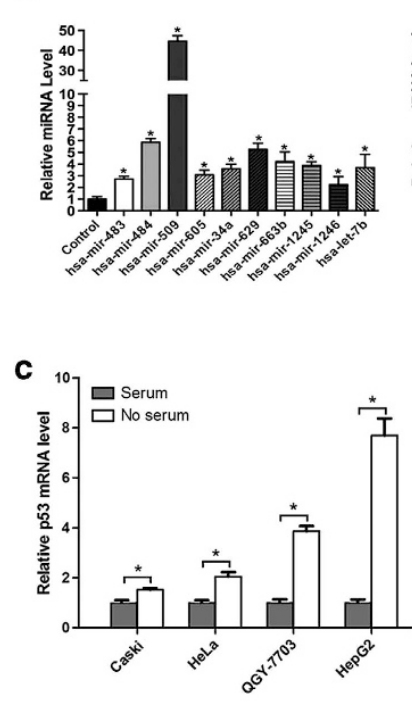

e
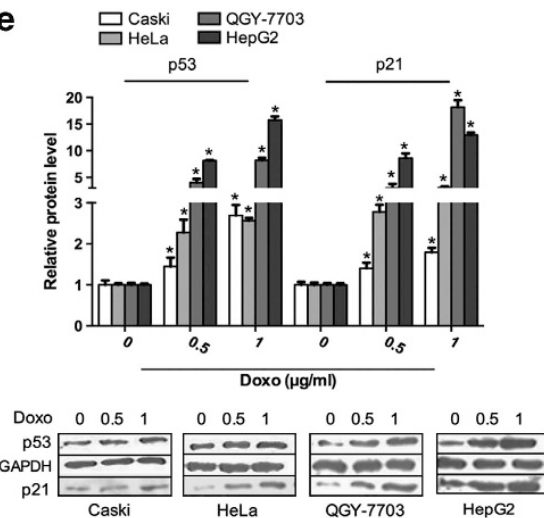

b
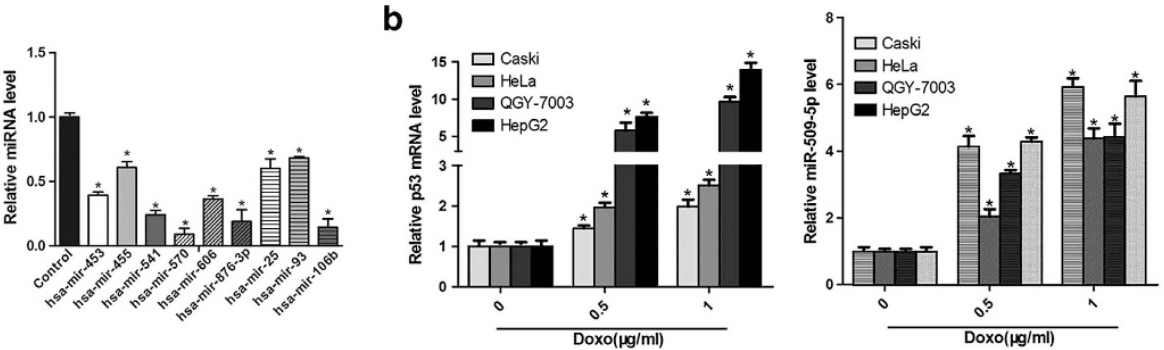

d
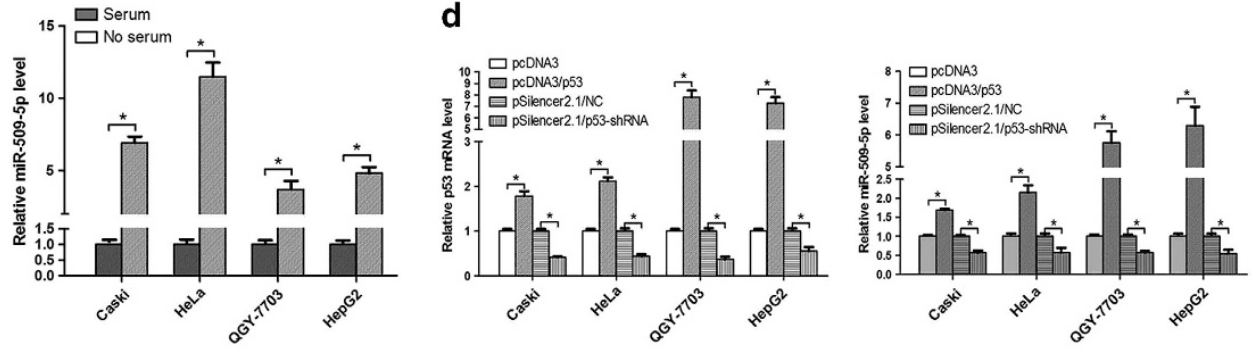

f

f Serum

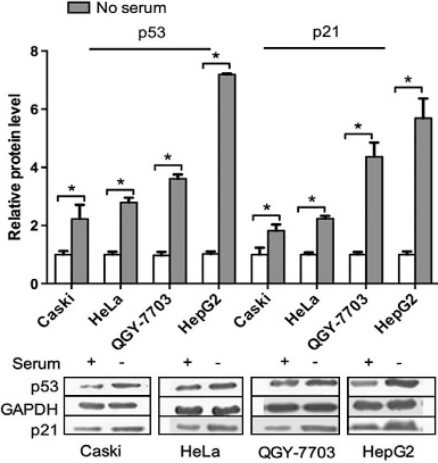

g

$\square$ pcDNA3

pcDNA3/p53

EpSilencer2.11NC
mul pSilencer2.1/p53-shRNA
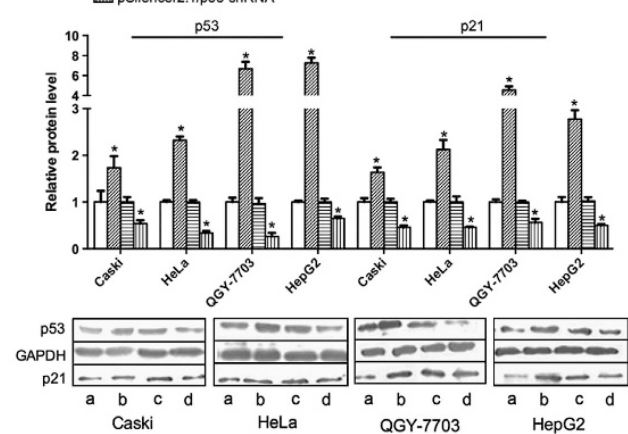

Figure 1 The miR-509-5p expression is modulated through the p53 pathway. (a) HeLa cells were transfected with pcDNA3/p53, and microarray was used to detect the differentially expressed miRNAs. The upregulated and downregulated miRNAs are shown. (b) p53 was induced in HeLa, Caski, QGY-7703 and HepG2 cells treated with 0.5 or $1.0 \mu \mathrm{g} / \mathrm{ml}$ doxo for $16 \mathrm{~h}$ (left panel). Under this condition, miR-509-5p was induced in the four cell lines (right panel). (c) Cells were grown in medium containing $10 \%$ or no FBS for $24 \mathrm{~h}$. p53 was induced in the four cells grown under serum starvation conditions (left panel), and miR-509-5p was induced in the four cell lines (right panel). (d) The qRTPCR analysis showed that the level of p53 mRNA increased or decreased (left panel) following transfection with pcDNA3/p53 or pSilencer2.1/p53-shRNA, respectively, and miR-509-5p expression was also subsequently induced or reduced in these four cell lines (right panel). (e) Western blot analysis showed that p53 was induced in HeLa, Caski, QGY-7703 and HepG2 cells treated with 0.5 or $1.0 \mu \mathrm{g} / \mathrm{ml}$ doxo for $16 \mathrm{~h}$. Accordingly, increased p21 protein expression level was also detected. GAPDH was used as an internal control. (f) Western blot analysis was performed to examine p53 and p21 protein expression level in the four cell lines (HeLa, Caski, QGY-7703 and HepG2 cells) grown in medium containing $10 \%$ or no FBS for $24 \mathrm{~h}$. GAPDH was used as an internal control. (g) The gain or loss of p53 protein expression level was measured in cells (HeLa, Caski, QGY-7703 and HepG2 cells) transfected with pcDNA3/p53 or pSilencer2.1/p53-shRNA as well as control plasmid by western blot analysis. The protein expression of p21 was also detected. GAPDH was used as an internal control. a, b, $c$ and d represent the cells transfected with pcDNA3, pcDNA3/p53, pSilencer2.1 and pSilencer2.1/p53shRNA, respectively ( ${ }^{*} P<0.05$ ) 
doxo or serum starvation treatment led to the upregulation of miR-509-5p expression (Figures $1 b$ and $c$, right panel). Furthermore, the gain or loss of p53 expression was used to alter the p53 expression in both mRNA and protein levels (Figure 1d, left panel; Figure 1g, top panel) and subsequently resulted in p21 protein-level alterations (Figure 1g, bottom panel). Knockdown of p53 resulted in the significant repression of miR-509-5p in the cells (Figure 1d, right panel), whereas overexpression of p53 resulted in a substantial induction of miR-509-5p expression in all cell lines (Figure 1d, right panel). These results demonstrate an important role of p53 in the induction of miR-509-5p in human cervical cancer and HCC cells.

p53 directly binds the promoter of miR-509-5p at the p53 response element. To determine whether p53 activates the miR-509-5p promoter, we cloned a 800-bp putative miR-509$5 p$ promoter carrying two p53 response elements (p53REs) into a pGL3 basic vector to generate pMir-509p-Luc-1
(Figure 2a). We tested pMir-509p-Luc-1 in HeLa cells. As shown in Figure 2b, overexpression of p53 increased miR-509-5p promoter activity by 2.8 -fold, whereas knockdown of p53 decreased the activity by 0.4 -fold. We also identified that doxo can induce the increase of the luciferase intensity of the miR-509-5p promoter (Figure 2c). Furthermore, a series of deletion constructs were generated to determine whether the two elements directly interact with p53 to mediate the induction of the miR-509-5p promoter activity by $\mathrm{p} 53$. We showed that the deletion of p53RE2 abolished the induction activity, whereas the deletion of p53RE 1 had no effect on p53-mediated induction of the miR-509-5p promoter activity, suggesting that only p53RE2 was responsible for p53-mediated miR-509-5p induction (Figure 2d). To further confirm the role of p53RE2 in miR-509-5p induction, chromatin immunoprecipitation (ChIP) assay was performed. Consistent with the luciferase results, we detected specific p53RE2 PCR product (Figure 2e) but not from p53RE1 after p53 overexpression. Quantification by qRT-PCR at the a

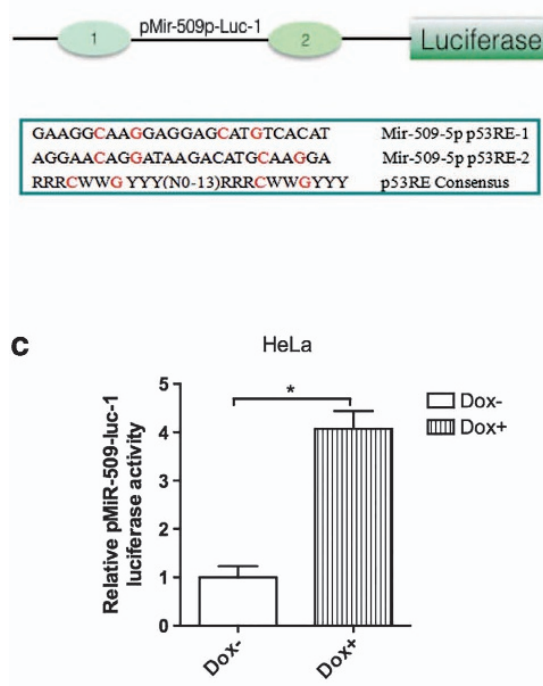

e

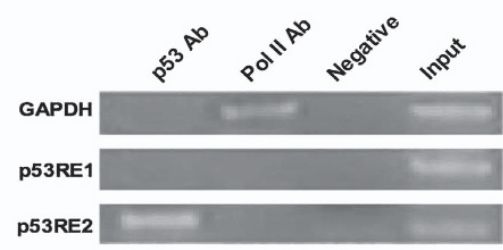

b HeLa

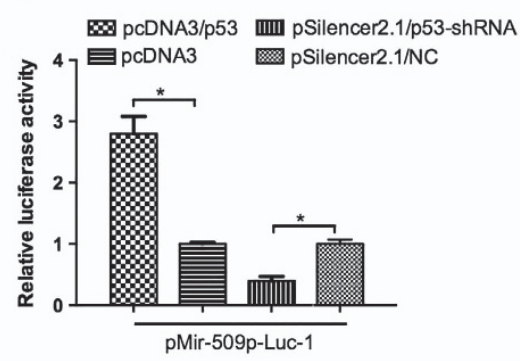

d

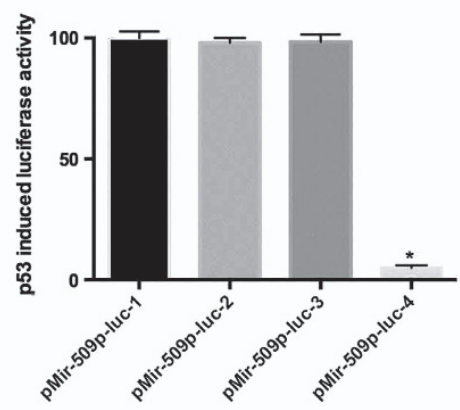

f

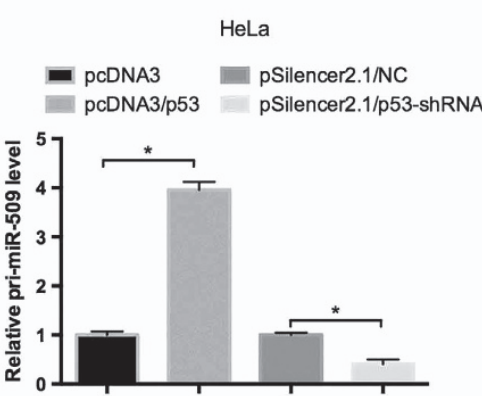

Figure 2 p53 induces the miR-509-5p promoter activity. (a) A schematic description of the putative miR-509-5p promoter with two potential p53 response elements, p53RE1 and p53RE2, is shown compared with the p53RE consensus, where $R=A$ or $G ; W=A$ or $T$ and $Y=C$ or $T$. $C$ and $G$ in red are the conserved nucleotides. (b) pMir-509p-Luc-1 luciferase assays in HeLa cells with overexpression or knockdown of p53. (c) pMir-509p-Luc-1 luciferase assays in HeLa cells treated with $1 \mu \mathrm{g} / \mathrm{ml}$ doxo. (d) Deletion analysis identifies p53RE2-mediated p53-induced miR-509-5p promoter luciferase activity. pMir-509p-Luc-2: p53RE1 was deleted; pMir-509p-Luc-3: the upstream sequence of pRE2 was deleted; pMir-509p-Luc-4: pRE2 sequence was deleted. (e) ChIP assay shows that p53 directly interacts with p53RE2. GAPDH sequence that can bind to Pol II antibody serves as a positive control. Normal mouse lgG was used as the negative control. (f) miR-509-5p primary transcript was detected by $q R T-P C R\left({ }^{*} P<0.05\right)$ 
miR-509-5p primary transcript level was further analyzed. Increased accumulation of miR-509-5p primary transcript was detected in cells overexpressing p53, and knockdown of p53 significantly repressed the expression of the miR-509-5p primary transcript (Figure 2f). Therefore, the results suggest that p53 induces miR-509-5p expression by directly interacting with its promoter.

MiR-509-5p suppresses cancer cell growth, migration and invasion in vitro. Given the ability of p53 to induce miR-509-5p, miR-509-5p is expected to have an impact on the malignant behaviors of cancer cells. First, we constructed a plasmid to overexpress miR-509-5p and synthesized an ASO (antisense methyoxy-modified nucleic acid oligo) of miR-509-5p (ASO-miR-509-5p). QRT-PCR analysis revealed approximately threefold higher expression of miR-509-5p in the miR-509-5p-transfected cells and a $50 \%$ reduction in the ASO-treated cells compared with the control cells (Figure 3a). MTT and colony formation assays were performed to analyze the cell viability and growth capacity. The results indicated that miR-509-5p suppressed HeLa, QGY-7703 and HepG2 cell viability and their long-term proliferative capacity (Figures $3 b$ and c), whereas ASO-miR509-5p exhibited the opposite effects (Figures $3 b$ and $c$ ). To determine whether miR-509-5p can affect the migration and invasion capacities of the cells, we detected changes in cell motility in the pri-miR-509-transfected cells using Transwell assays. The upregulation of miR-509-5p significantly suppressed cell migration of the HeLa and QGY-7703 cells, as measured by the Transwell assay in the absence of Matrigel. However, cell migration was significantly promoted when the cells were transfected with ASO-miR-509-5p compared with the ASO-NC-transfected cells (Figures $3 d$ and e). Furthermore, Transwell assays performed in the presence of $2 \mathrm{mg} / \mathrm{ml}$ Matrigel showed that overexpression of miR-509-5p decreased cell invasion compared with the control cells. In contrast, an increase in the invasion ability of the ASO-miR-509-5p-transfected cells was observed compared with the ASO-NC-transfected cells (Figures $3 f$ and g). Therefore, miR-509-5p exerts suppressive effects on cell growth, invasion and migration in human cervical cancer and HCC cell lines.

Mdm2 is a target of miR-509-5p-mediated post-transcrip-
tional repression. Bioinformatics analyses predicted that
Mdm2 might be a putative target gene of miR-509-5p
(Figure 4a). First, we examined the expression levels of
miR-509-5p, Mdm2 and p53 to determine their reciprocal
correlation. As expected, miR-509-5p and p53 were gen-
erally expressed at low levels, whereas Mdm2 was generally
upregulated in the cervical cancer and HCC tissues
compared with their adjacent nontumor tissues (Figure $4 b$ ).
QRT-PCR (Figure $4 c$ ) and western blot (Figure $4 d$ ) analyses
confirmed that the ectopic expression of miR-509-5p
substantially suppressed Mdm2 expression, and the results
were also confirmed by another two primers (Supplementary
Figure S3). To further determine the specificity of the miR-
$509-5 p / M d m 2$ interaction, we used ASO-miR-509-5p to
knock down its level. As shown in Figures $4 c$ and d, ASO-
miR-509-5p was able to enhance Mdm2 expression.
Furthermore, to determine whether miR-509-5p directly targets Mdm2, we constructed an EGFP reporter carrying the Mdm2 $3^{\prime}$-UTR with a putative miR-509-5p-binding site. EGFP expression was reduced by $\sim 40 \%$ in the miR-509-5ptransfected cells compared with the vector control group (Figure 4e). This suppression of EGFP expression was abolished in the cells co-transfected with the Mdm2 $3^{\prime}$-UTRmut (Figure $4 \mathrm{e}$ ), in which the seed sequence was mutated (Figure 4a). However, EGFP activity was increased in the cells co-transfected with ASO-miR-509-5p and the EGFP reporter carrying Mdm2 $3^{\prime}$-UTR, whereas ASO-miR-509-5p had no effect on the activity of the Mdm2 $3^{\prime}$-UTR-mut construct. We confirmed Mdm2 mediated the miR-509-5pinduced cell phenotype alterations, because ectopic expression of Mdm2 counteracted the suppressive effects of miR-509-5p on cell viability and proliferation in HeLa and QGY-7703 cells (Figures $4 \mathrm{f}$ and $\mathrm{g}$ ).

To provide a more definitive function of Mdm2 in miR-509$5 p$-mediated proliferation, we used Mdm2 siRNA to transfect HeLa cells. Consistent with the role of miR-509-5p, knockdown of Mdm2 resulted in a suppressed proliferation of HeLa cells (Supplementary Figure S4). Furthermore, miR-509-5p did not have further growth inhibitory effects in Mdm2 siRNA-transfected cells (Figures 4h and i). Therefore, miR-509-5p acts as a tumor suppressor in cervical cancer and HCC cells by directly targeting Mdm2, and this specific silencing of $\mathrm{Mdm} 2$ by miR-509-5p accounts, at least in part, for the miR-509-5pmediated inhibition of cervical cancer and HCC cell growth.

Implication of miR-509-5p participation in the Mdm2/p53 signaling pathway. Mdm2 is a well-known oncogene that plays an important role in the ubiquitination and subsequent proteasomal degradation of the p53 protein, and Mdm2 may repress the cancer cell cycle and promote apoptosis. ${ }^{23}$ However, the underlying mechanism of p53 regulation by miR-509-5p is not understood. To determine whether miR-509-5p mediated the alteration of p53 expression, we ectopically expressed miR-509-5p in HeLa cells. The results revealed that miR-509-5p induced the accumulation of $p 53$, and antagonizing miR-509-5p repressed p53 expression (Figure 5a, bottom panel). Furthermore, we confirmed that the ubiquitinated p53 was reduced when miR-509-5p was overexpressed, whereas cells transfected with ASO-miR509-5p had increased level of ubiquitinated p53 (Figure 5a, top panel). As HeLa cells express HPV E6 that mediates p53 polyubiquitination and degradation, we examined whether miR-509-5p affected the expression of E6. The result showed that E6 expression was not affected by miR-509$5 p$ (Supplementary Figure S5). Moreover, we selected an HPV negative cell line C33A and confirmed miR-509-5p can also inhibit Mdm2 and activate p53 expression significantly (Supplementary Figure S6). We further defined whether miR-509-5p regulated p53 mRNA and protein levels by downregulating Mdm2 expression during doxo treatment. ASO-miR-509-5p induced Mdm2 expression and caused reduction of the p53 level by $60 \%$. However, when the ASO-miR-509-5p-transfected cells were treated with doxo, the Mdm2 expression was reversed by $30 \%$ (compared with ASO-miR-509-5p group with no doxo induction), and the p53 level was reversed by $40 \%$ (Figure $5 \mathrm{~b}$ ). 
a
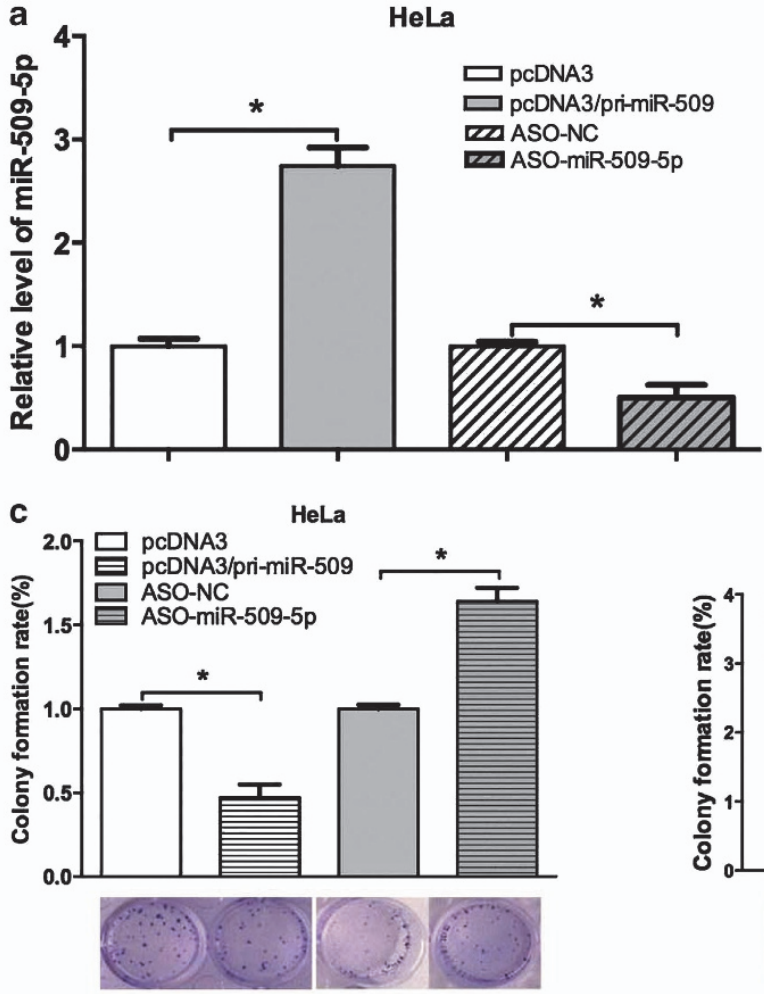

d

Hela
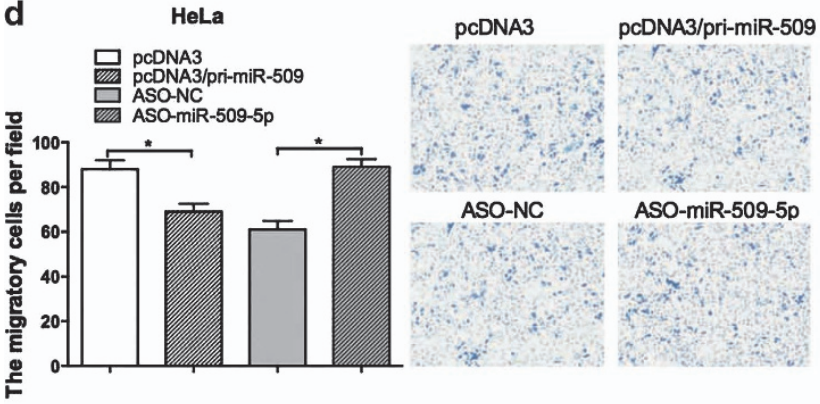

f

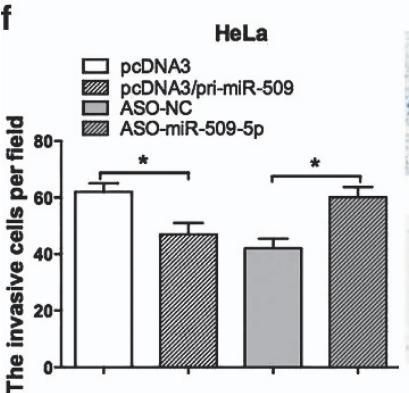

pcDNA3

pcDNA3/pri-miR-509

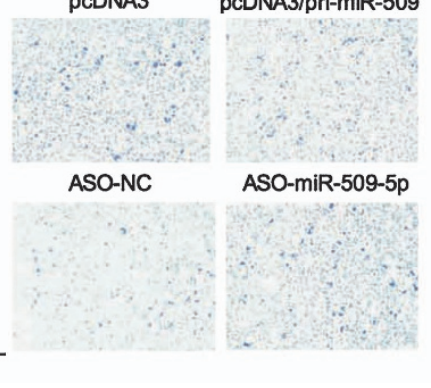

b

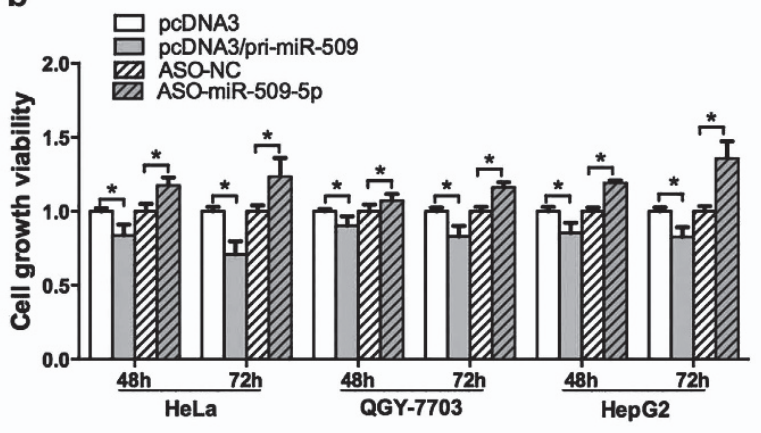

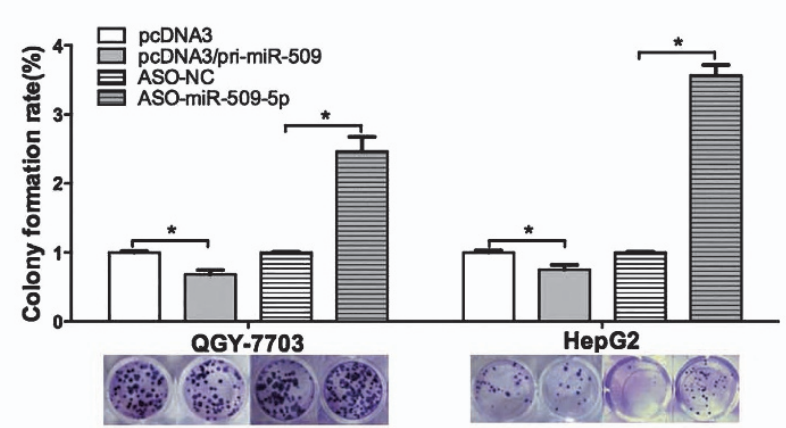

e

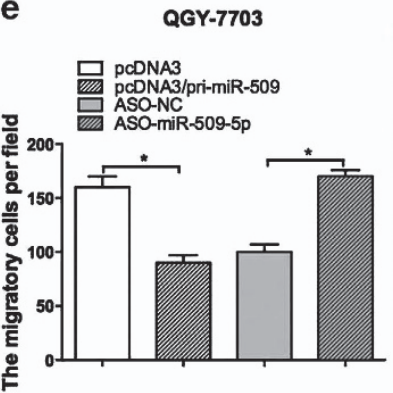

pcDNA3

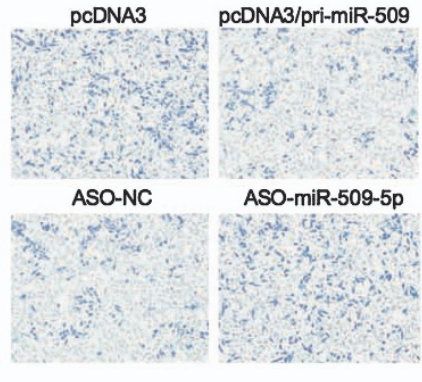

g
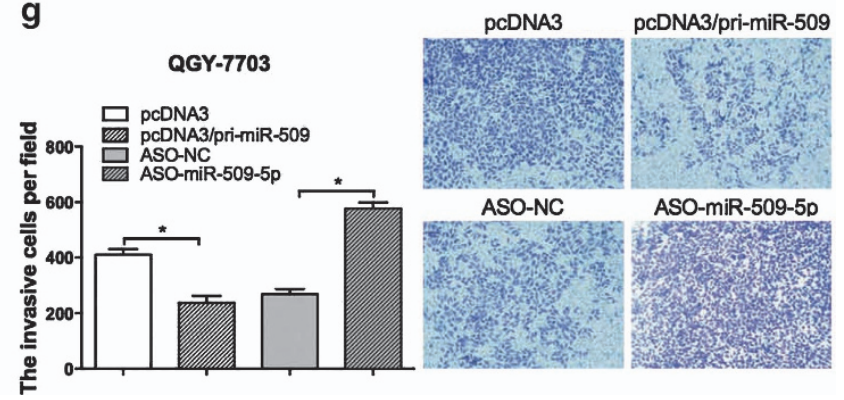

Figure 3 miR-509-5p serves as a tumor suppressor. (a) qRT-PCR was performed to examine the alterations of miR-509-5p expression after transfection with pri-miR-509 and ASO-miR-509-5p in HeLa cells. U6 snRNA was used as an internal control. (b and $\mathbf{c}$ ) The effects of overexpression or knockdown of miR-509-5p on cell viability were detected using an MTT assay, and the long-term effects on proliferative capacity were examined after transfection using a colony formation assay in HeLa, QGY-7703 and HepG2 cells. (d and e) Transwell migration assays were performed with HeLa and QGY-7703 cells transfected with pri-miR-509, ASO-miR-509-5p and the corresponding control vectors. Transwell assays without Matrigel demonstrated that miR-509 significantly decreased the migration of HeLa and QGY-7703 cells when compared with the control vector groups. The results were consistent when miR-509-5p was depleted. (f and $\mathbf{g}$ ) Transwell assays with Matrigel demonstrated that miR-509 overexpression significantly promoted the invasion of HeLa and QGY-7703 cells when compared with the control vector groups. The results were consistent when miR-509-5p was depleted $\left({ }^{\star} P<0.05\right)$ 
a

c

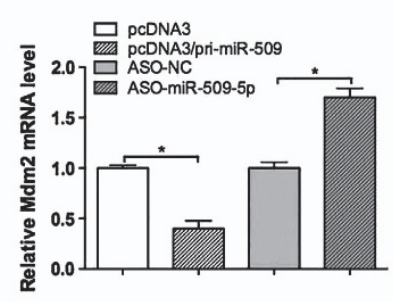

f

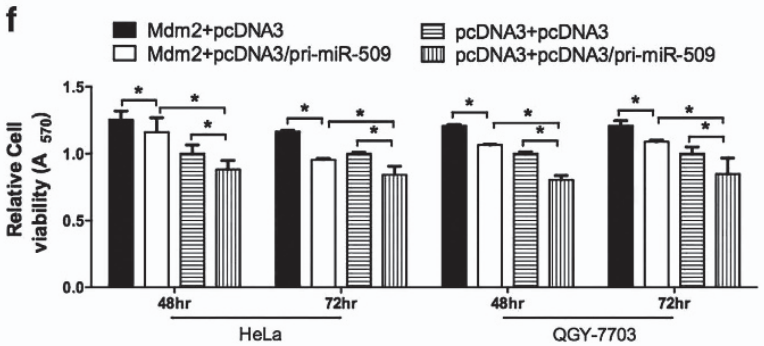

h

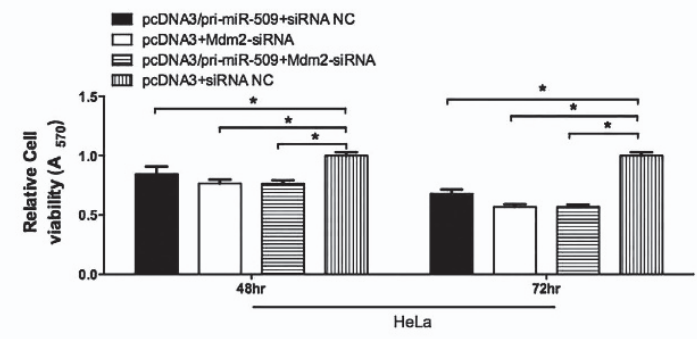

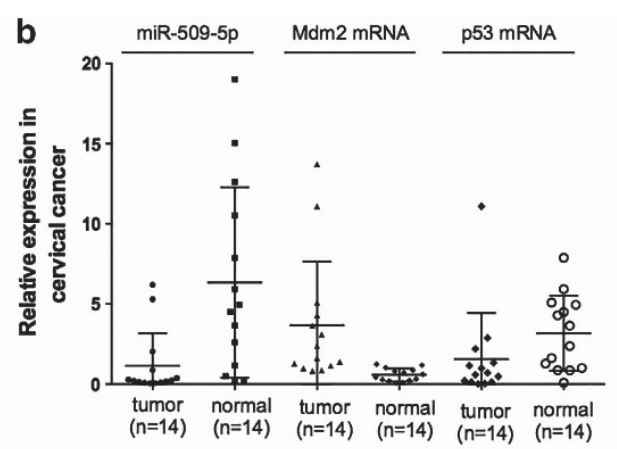
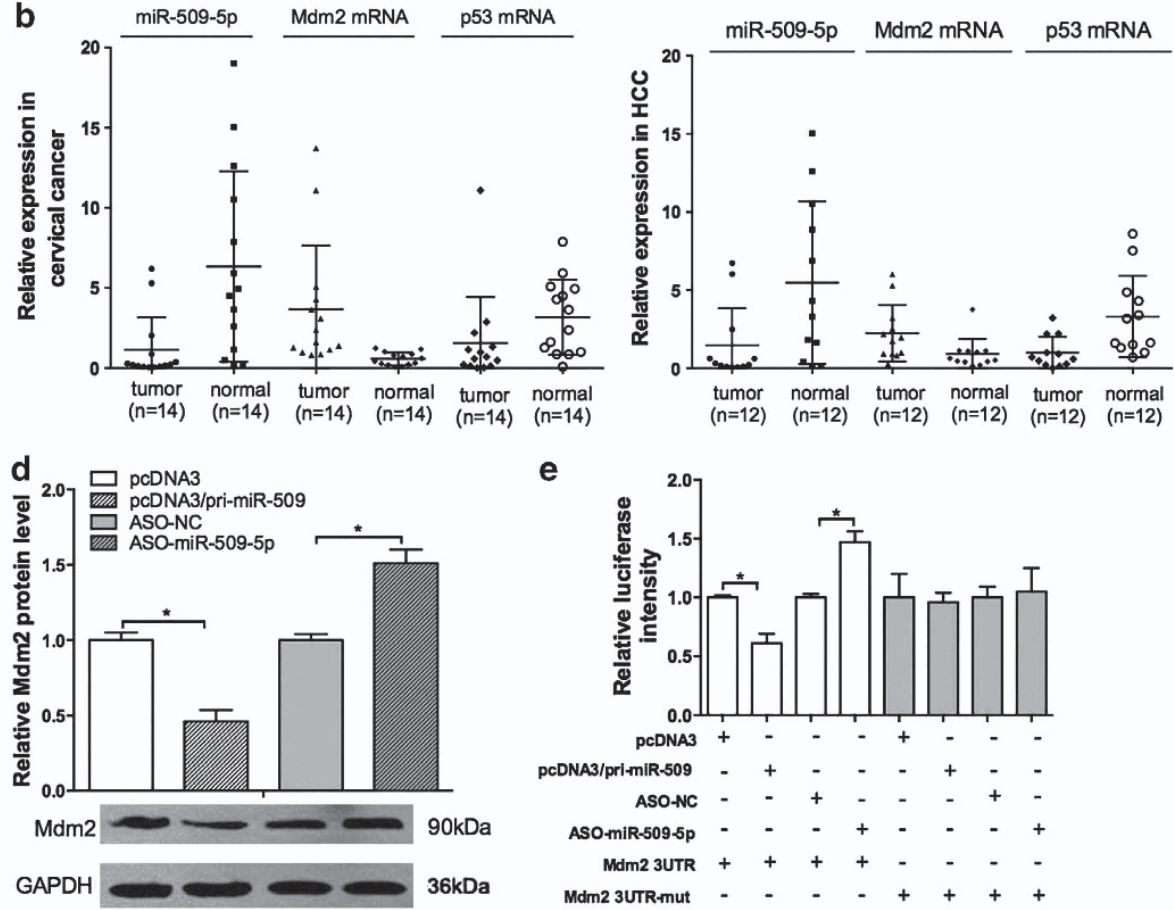

e

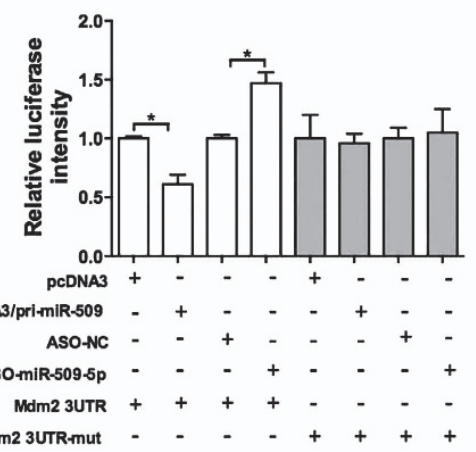

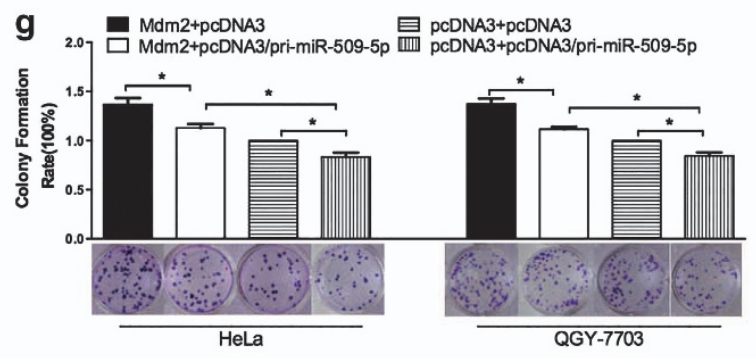

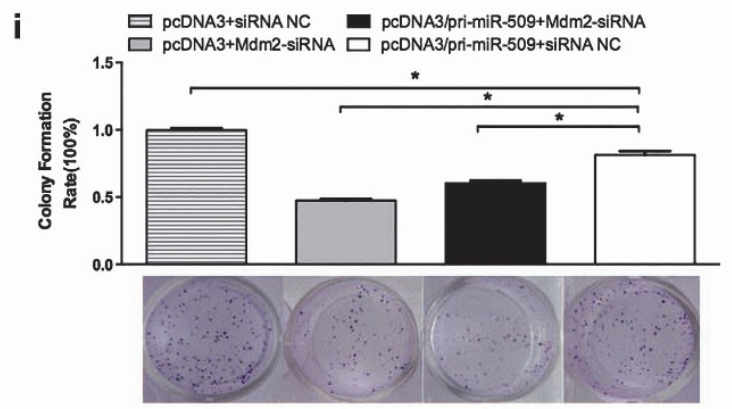

HeLa

Figure 4 miR-509-5p directly targets Mdm2 and inhibits its expression. (a) A schematic of the bioinformatics predicted seed region in the $3^{\prime}$-UTR of Mdm2 is shown above; the mutated $3^{\prime}$-UTR used in this study is also shown. (b) Expression of miR-509-5p, Mdm2 and p53 in the 14 pairs of matched cervical tumor specimens and in the 12 pairs of matched HCC tissues. (c) qRT-PCR showed the suppression of Mdm2 expression by miR-509-5p. The HeLa cells were transfected with the empty vector or miR-509-5p for $24 \mathrm{~h}$ before harvesting. (d) Western blot analysis was used to detect Mdm2 protein expression when HeLa cells were transfected with pcDNA3/pri-miR-509 or ASO-miR-5095p. (e) The effect of miR-509-5p or ASO-miR-509-5p on the EGFP activity of EGFP-Mdm2-3'-UTR and EGFP-Mdm2-3'-UTR-mut, in which the putative miR-509-5p-binding site was mutated. For the EGFP reporter assays, HeLa cells were transfected with a miR-509-5p expression vector or ASO-miR-509-5p oligo and then harvested for lysis $48 \mathrm{~h}$ after transfection. The MTT assay (f) and colony formation assay (g) were performed to assess the HeLa and QGY-7703 cell growth alterations in the rescue experiment to further confirm that miR-509-5p acts as a tumor suppressor. ( $h$ and i) MTT and colony formation assays were performed to detect the effect of miR-509-5p in Mdm2-siRNAtransfected cells $\left({ }^{*} P<0.05\right)$

We then examined the effect of miR-509-5p-mediated p53 promotion on the levels of p21 and bak, both of which are direct targets of $p 53 .{ }^{22}$ As shown in Figures $5 c$ and d, miR509-5p overexpression led to increased mRNA and protein levels of p21 and bak protein, whereas ASO-miR-509-5p reduced the p21 and bak expression levels. Given that p53 plays a critical role in the regulation of p21 and bak, we performed cell cycle analysis in the miR-509-5p-transfected 
a

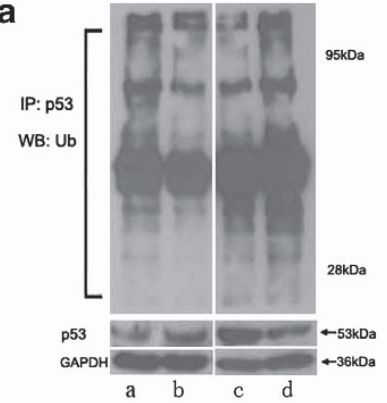

b

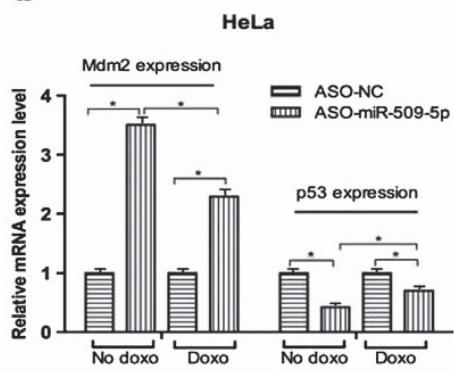

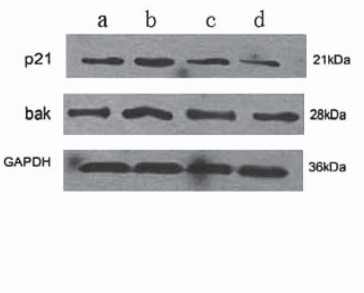

d

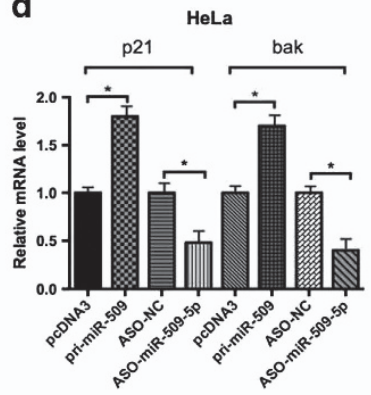

e

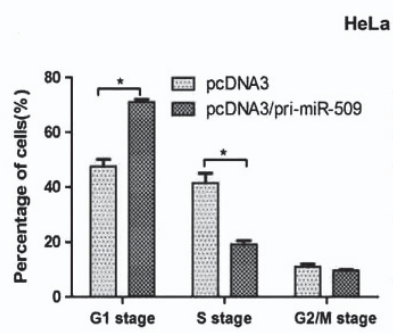

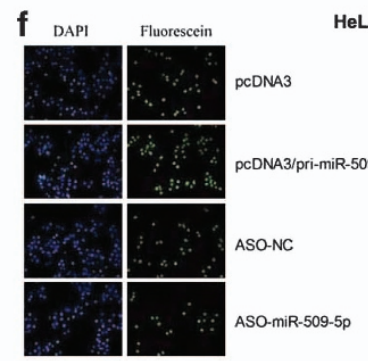

HeLa
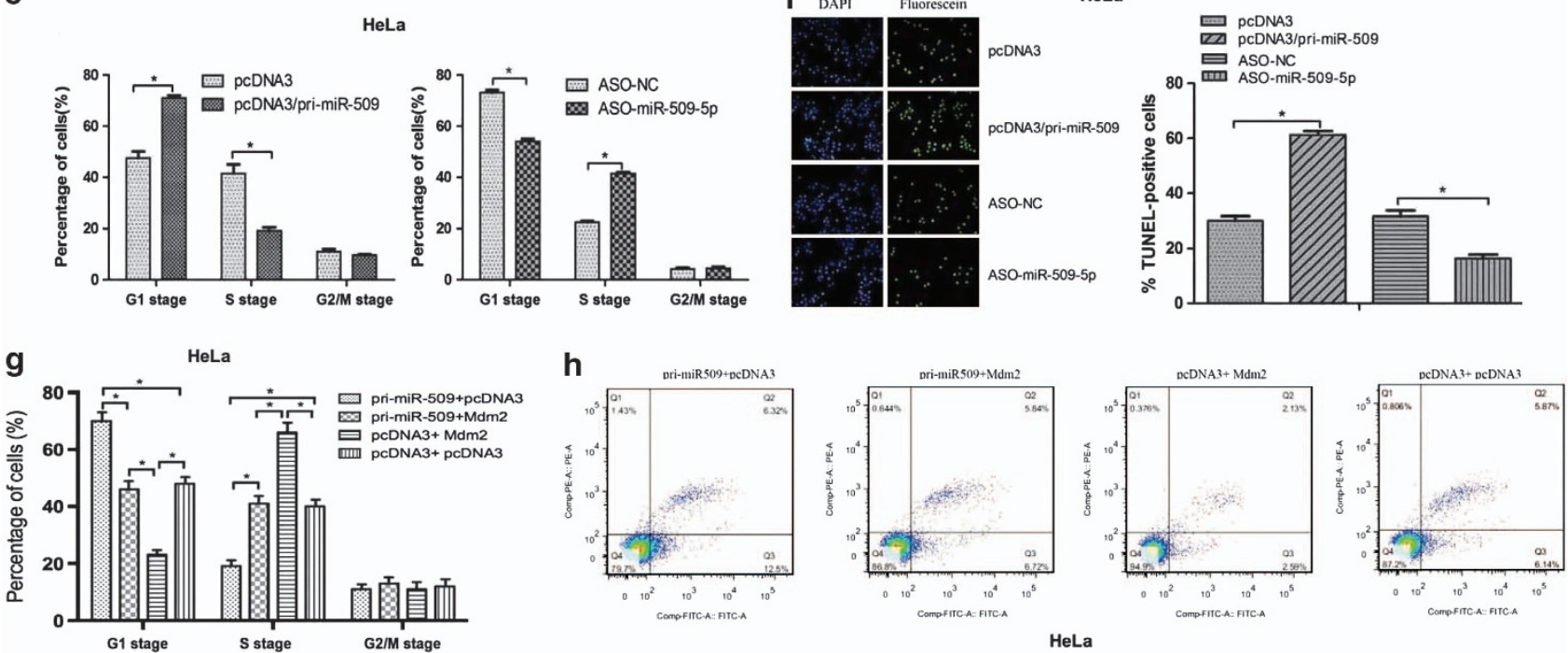

Figure 5 Role of miR-509-5p in the regulation of cell cycle and apoptosis. (a) Overexpression of miR-509-5p enhanced p53 ubiquitination, and inhibition of miR-509-5p by ASO-miR-509-5p attenuated endogenous p53 ubiquitination in HeLa cells (top panel). The bottom panel shows the effect of miR-509-5p or ASO-miR-509-5p on p53 expression. a, b, c and d represent the cells transfected with pcDNA3, pcDNA3/pri-miR-509, ASO-NC and ASO-miR-509, respectively. (b) The mRNA level of Mdm2 and p53 in the presence of ASO-miR-509-5p with or without treatment of doxo. (c) The HeLa cells were treated with miR-509-5p or ASO-miR-509-5p for 48 h and were then lysed. Western blot analysis was used to detect p21 and bak expression. a, b, $c$ and d represent the cells transfected with pcDNA3, pcDNA3/pri-miR-509, ASO-NC and ASO-miR509, respectively. (d) qRT-PCR was used to detect the mRNA levels of p21 and bak in HeLa cells. (e and f) Cell cycle progression and apoptosis were analyzed using FACS and TUNEL assay in HeLa cells. ( $\mathbf{g}$ and $\mathbf{h})$ Rescue experiment to detect miR-509-5p effect in Mdm2-transfected HeLa cells $\left({ }^{*} P<0.05\right)$

cells. We found that miR-509-5p increased the percentage of cells in G1 phase by $\sim 35 \%$ and reduced the S-phase cell population by $\sim 53 \%$ (Figure $5 e$, left panel); however, ASOmiR-509-5p reduced the G1-phase cell population by $\sim 24 \%$ and increased S-phase cell population by $\sim 51 \%$ (Figure 5 e, right panel). Furthermore, miR-509-5p enhanced HeLa cell apoptosis, whereas ASO-miR-509-5p reduced HeLa cell apoptosis (Figure 5f).

To further investigate whether miR-509-5p affected cell cycle and apoptosis was mediated by Mdm2, Mdm2 was transfected into miR-509-5p-transfected HeLa cells. We observed that miR-509-5p inhibited cell cycle and induced apoptosis was rescued in the presence of Mdm2 (Figures $5 \mathrm{~g}$ and $\mathrm{h}$ ). Therefore, these results collectively indicate that miR509-5p suppresses the Mdm2-mediated ubiquitination and degradation of p53, and the accumulated p53 induces cell cycle arrest and promotes apoptosis.

\section{Discussion}

MiRNAs have been implicated in many critical biological processes. The aberrant expression of miRNAs observed in various human cancers suggests that miRNAs may play important roles in tumorigenesis. ${ }^{24,25}$ For example, it has been reported that $\mathrm{miR}-15 \mathrm{a}$ and $\mathrm{miR}-16-1$ are downregulated in B-cell chronic lymphocytic leukemia (CLL), ${ }^{26}$ and miR-143 and miR-145 are downregulated in colorectal cancer. ${ }^{27}$ Amplification or overexpression of the miR-17-92 cluster and miR-155 was reported in lymphomas. ${ }^{28}$ In addition, $>50 \%$ of human miRNA genes are located in cancerassociated genomic regions or at fragile sites. ${ }^{29,30}$ In this study, we found that miR-509-5p can suppress the cell growth capacity of human cervical cancer and HCC cell lines, as well as delay the G1/S-phase transition of the cell cycle and facilitate apoptosis. miR-509-5p is generally downregulated in human cervical cancer and HCC tissues compared with the adjacent nontumor tissues, suggesting that miR-509-5p functions as tumor suppressor and plays an important role in tumorigenesis.

Because of the low expression and cell growth suppression of miR-509-5p in cervical cancer and HCC cells, we wondered whether it was under the control of the tumor suppressor p53 that acts as a transcriptional regulator of numerous genes involved in cell cycle arrest, apoptosis and senescence. 
The p53 target genes can be classified as those that primarily induce cell cycle arrest (e.g., the cyclin-dependent kinase inhibitor CDKN1A/p21) and those that mediate apoptosis (e.g., bak); ${ }^{31}$ thus, we speculated that p53 may induce miR509-5p expression. It has been shown that p53 regulates the expression of a set of specific miRNAs. For example, miR-34a has been shown to be a direct transcriptional target of $p 53$, and this miRNA has been shown to regulate cellular apoptosis and senescence. ${ }^{32}$ The p53 protein binds to the promoter of miR-34a and increases the expression of miR-34a in response to stress. Inactivation of endogenous miR-34a strongly inhibits p53-dependent apoptosis. To determine whether p53 regulates the expression of more miRNAs, we used a miRNA array to screen for the differential expression of miRNAs when p53 was overexpressed in HeLa cells. Among the 19 differentially expressed miRNAs, the upregulation of miR-509-5p was the most significant change. Furthermore, p53 mediated upregulation of miR-509-5p in cervical cancer and HCC cell lines under stress conditions, such as doxo or serum starvation, as well as following overexpression or depletion of $p 53$. We also confirmed that $p 53$ can directly bind and activate the promoter of miR-509-5p using luciferase reporter and chip assays.

Generally, miRNAs exert functions by binding to the $3^{\prime}$-UTR of the target gene to repress its expression. ${ }^{1}$ To identify the target genes of miR-509-5p, we first used bioinformatic analysis to predict a 100 candidate target genes of miR-509$5 \mathrm{p}$. Combining the prediction results and the function of miR509-5p described above, Mdm2 was chosen as a target gene for further study. Using an EGFP reporter assay, we confirmed the direct binding of miR-509-5p to the Mdm2 3'-UTR; qRT-PCR and western blot analyses showed that miR-509-5p downregulates Mdm2 expression in cervical cancer and HCC cell lines. Furthermore, qRT-PCR showed the inverse correlation between miR-509-5p and Mdm2 expression in the cancer and adjacent nontumor tissues in clinical specimens of cervical cancer and HCC. Moreover, ectopic expression of Mdm2 counteracted the phenotypes induced by miR-509-5p in the cancer cell lines and knockdown of Mdm2 had similar effects compared with overexpression of miR-509-5p. These results suggest that Mdm2 is a direct and functional target gene of miR-509-5p.

As an E3 ubiquitin ligase, Mdm2 binds to p53 to mediate its degradation; in addition, Mdm2 is overexpressed in many human tumors to antagonize p53 function that plays an important role in cancer initiation and development. ${ }^{15,16,33}$ Although some proteins have been found to regulate Mdm2 expression in cancer cells, such as PTEN ${ }^{34}$ IGF- $^{35}$ and p53, miRNAs such as miR-605 can also target Mdm2 to repress its expression, ${ }^{36}$ resulting in the formation of a regulatory network. Here, we identified a new regulator of the Mdm2/ p53 regulatory loop. Our results indicate that depletion of miR-509-5p increases the level of Mdm2 protein and p53 ubiquitination, whereas overexpression of miR-509-5p decreases p53 ubiquitination that in turn influences the expression of the p53 target genes, p21 and bak. Altogether, p53 can directly bind to its consensus element (p53RE2) in miR-509-5p promoter that results in the induction of miR-509$5 p$ and in turn represses Mdm2 activity to increase the p53 level. Thus, miR-509-5p, Mdm2 and p53 form a positive

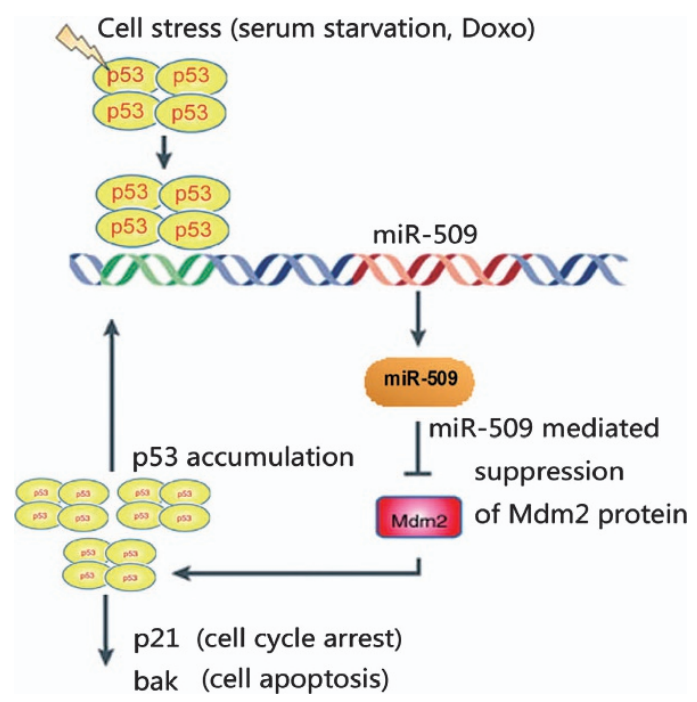

Figure 6 A proposed model describing the participation of miR-509-5p to form a positive feedback loop. In response to cellular stress, miR-509-5p expression is enhanced because of p53 activation, and this miR-509-5p upregulation then directly targets and represses Mdm2 expression and increases the level of p53 protein, leading to the activation of p21 and bak, therefore inducing cell cycle arrest and apoptosis

feedback loop (Figure 6) that provides new insights into the p53-mediated regulation of oncogenesis.

In summary, we have demonstrated here that (1) p53 directly binds to the promoter of miR-509-5p and activates its expression; (2) miR-509-5p suppresses HeLa, QGY-7703 and HepG2 cell growth; (3) miR-509-5p post-transcriptionally represses Mdm2 expression; (4) overexpression of miR-509$5 p$ increases the transactivation activity of p53, resulting in the upregulation of p21 and bak; and (5) miR-509-5p induces cell cycle repression and apoptosis through Mdm2/p53 pathway. Together, our results have defined a mechanism by which miR-509-5p participates in the Mdm2/p53 regulatory pathway and have provided new insights into cervical cancer and HCC tumorigenesis, thus providing the basis for the development of miRNA-targeted therapies for cervical cancer and HCC.

\section{Materials and Methods}

Human tissue specimens and cell lines. Cervical cancer tissue specimens from 14 cervical cancer patients were obtained from the Tumor Bank Facility of Tianjin Medical University Cancer Institute and Hospital and National Foundation of Cancer Research (TBF of TMUCIH and NFCR). Fourteen pairs of fresh specimens were collected at the Cancer Center of Sun Yat-sen University of Medical Science, including human liver tumor and adjacent nontumor tissue from patients undergoing hepatectomy for HCC, in accordance with the ethical standards of the institutional committee. These tissue were stored frozen at $-80^{\circ} \mathrm{C}$ according to a standard procedure. The human cervical cancer cell lines (HeLa and Caski) and HCC cell line (QGY-7703) were grown in RPMI-1640 medium supplemented with $10 \%$ fetal bovine serum (FBS) and $1000 \mathrm{U} / \mathrm{ml}$ penicillin/streptomycin (P/S); HepG2 cells were grown in MEM- $\alpha$ supplemented with $20 \% \mathrm{FBS}$ and $1000 \mathrm{U} / \mathrm{ml} \mathrm{P} / \mathrm{S}$. These human cancer cell lines were incubated at $37^{\circ} \mathrm{C}$ in a humidified atmosphere with $5 \% \mathrm{CO}_{2}$.

Cell transfection. The cells were transfected with Lipofectamine 2000 (Invitrogen, Carlsbad, CA, USA) according to the manufacturer's instructions. Transfection efficiency was monitored by fluorescence microscopy $48 \mathrm{~h}$ after transfection with $\mathrm{pcDNA3/EGFP.}$

RNA preparation and qRT-PCR. RNA extraction of the cells or tissue samples was performed using the mirVana miRNA Isolation Kit (Ambion, Austin, 
TX, USA) according to the manufacturer's instructions. Large RNAs (>200 nt) and small RNAs $(<200 \mathrm{nt})$ were separated and purified in this procedure. For miRNA detection, $2 \mu \mathrm{g}$ of small RNA was reverse transcribed to cDNA using M-MLV (Promega, Madison, WI, USA). QRT-PCR analysis for miR-509-5p was performed in triplicate with the SYBR Premix Ex Taq TM kit (TaKaRa, Dalian, Liaoning, China) according to the manufacturer's instructions. The expression of miR-509-5p was normalized to the levels of U6 RNA. To detect other genes, $5 \mu \mathrm{g}$ of large RNA was reverse transcribed to CDNA using oligo(dT) primers and M-MLV. QRT-PCR was used to determine the expression levels of Mdm2, p53, E6, p21 and bak using the primers described in Table 1. The levels of these transcripts were normalized to the levels of $\beta$-actin.

Plasmid construction. To construct a plasmid expressing miR-509-5p, a 400-bp DNA fragment carrying pri-miR-509-5p was inserted between the BamHI and Hindlll sites of pcDNA3. The EGFP reporter vector pcDNA3/EGFP was constructed as previously described. The $3^{\prime}$-UTR, including the target sites, of Mdm2 was amplified by qRT-PCR and cloned downstream of EGFP between the BamHI and EcoRI sites. Similarly, the $3^{\prime}$-UTR mutant, which contained mutated miR-509-5p-binding sites, was cloned into pcDNA3/EGFP between the same sites. The primer sequences used for qRT-PCR amplification are shown in Table 1. Sequences that were inserted into the plasmid were verified by DNA sequencing.

To clone the putative miR-509-5p promoter, we amplified a DNA fragment $(800 \mathrm{bp})$ from the genomic DNA of HeLa cells. PCR primers were p509-Nhel-S and p509-Xhol-AS (Table 1). The PCR product was then subcloned into pGL3 basic (Clontech, Mountain View, CA, USA). The similar strategy was used to make deletion constructs. PCR primer sequences are in Table 1. All PCR products were verified by DNA sequencing.
Cell biology assays. For the MTT assay, HeLa, QGY-7703 and HepG2 cells were seeded in 96 -well plates at a density of $4000 \mathrm{cells} / \mathrm{well}$. After $48 \mathrm{~h}$ of transient transfection, the cells were incubated with $15 \mu \mathrm{l}$ of MTT at a final concentration of $0.5 \mathrm{mg} / \mathrm{ml}$ at $37^{\circ} \mathrm{C}$ for another $4 \mathrm{~h}$. The medium was then removed, and the precipitated formazan was dissolved in $100 \mu$ l of dimethyl sulfoxide (DMSO). After shaking for $15 \mathrm{~min}$, the absorbance at $570 \mathrm{~nm}$ (A 570) was detected using a Quant universal microplate spectrophotometer (Bio-Tek Instruments, Winooski, VT, USA).

For the colony formation assay, after transfection, the cells were counted and seeded in 12-well plates (in triplicate) at a density of 100 cells/well. The culture medium was replaced every 3 days. Colonies were counted only if they contained more than 50 cells, and the number of colonies was counted from day 6 of seeding after the cells were stained with crystal violet. The rate of colony formation was calculated using the following equation: colony formation rate $=$ (number of colonies/number of seeded cells) $\times 100 \%$.

For the in vitro cell invasion and migration assays, the assays were performed using Transwell chambers (pore size of $8 \mu \mathrm{M}$; Costar, Corning, NY, USA) with or without $2 \mathrm{mg} / \mathrm{ml}$ Matrigel (Clontech). The transfected cells were resuspended in serum-free medium, and $200 \mu$ l of the cell suspension $\left(4 \times 10^{4}\right.$ cells) was added to the upper chamber. Complete medium was added to the bottom wells of the chambers. For the screen, the cells that had not migrated after $20 \mathrm{~h}$ were removed, and the cells that adhered to the lower membrane of the inserts were counted, as previously described. Images of three different fields were taken. The mean of triplicate assays for each experimental condition was used. For the invasion assays, the cells that had traversed to the lower membrane after $24 \mathrm{~h}$ were counted.

MiRNA microarray. Cloning and sequence amplification of the microRNAs was performed using a microRNA labeling technique. Briefly, $30 \mu \mathrm{g}$ of purified

Table 1 Oligonucleotides used in this study

\begin{tabular}{|c|c|}
\hline Name & Sequence $\left(5^{\prime}-3^{\prime}\right)$ \\
\hline $\begin{array}{l}\text { miR-509-5p RT } \\
\text { U6 RT } \\
\text { miR-509-5p Fwd } \\
\text { U6-Fwd } \\
\text { Reverse } \\
\text { pri-miR-509-S } \\
\text { pri-miR-509-AS } \\
\text { P509-Nhel-S } \\
\text { P509-Xhol-AS } \\
\text { pMir-509p-Luc-2- S } \\
\text { pMir-509p-Luc-2- AS } \\
\text { pMir-509p-Luc-3- S } \\
\text { pMir-509p-Luc-3- AS } \\
\text { pMir-509p-Luc-4- S } \\
\text { pMir-509p-Luc-4- AS } \\
\text { Mdm2-509-3'-UTR-S } \\
\text { Mdm2-509-3'-UTR-AS } \\
\text { Mdm2-509-3'-UTR-MS } \\
\text { Mdm2-509-3'-UTR-MA } \\
\text { Mdm2- primer1-S } \\
\text { Mdm2- primer1-AS } \\
\text { Mdm2- primer2-S } \\
\text { Mdm2- primer2-AS } \\
\text { Mdm2- primer2-S } \\
\text { Mdm2- primer2-AS } \\
\text { p53-primer1-S } \\
\text { p53-primer1-AS } \\
\text { p53-primer2-S } \\
\text { p53-primer2-AS } \\
\text { p53-primer3-S } \\
\text { p53-primer3-AS } \\
\text { HpV E6-S } \\
\text { HpV E6-AS } \\
\text { bak sense } \\
\text { bak antisense } \\
\text { p21 sense } \\
\text { p21 antisense } \\
\beta \text {-Actin-S } \\
\beta \text {-Actin-AS }\end{array}$ & $\begin{array}{l}\text { GTCGTATCCAGTGCAGGGTCCGAGGTGCACTGGATACGACTGATTGC } \\
\text { GTCGTATCCAGTGCAGGGTCCGAGGTATTCGCACTGGATACGACAAAATATGGAAC } \\
\text { TGCGGTACTGCAGACAGTGGCAA } \\
\text { TGCGGGTGCTCGCTTCGGCAGC } \\
\text { CCAGTGCAGGGTCCGAGGT } \\
\text { CGAGGATCCAATGGCACCACAACTTG } \\
\text { CGGAATCTGAGGTAGTCCAGCATGGAAG } \\
\text { GCCTAGCTAGCGTGTTCATCCCGTGCCTGTTACC } \\
\text { ACGAACTCGAGCTGCAGAATCCAATCCAC } \\
\text { CAGTGGTACCCTTACATGGATGGCGACAGGCA } \\
\text { ACGAACTCGAGCTGCAGAATCCAATCCAC } \\
\text { CCGGAATTCGTTAATGCTTGCAAGTAGCAATGTGA } \\
\text { ACGACTCGAGCTGCAGAATCCAATCCAC } \\
\text { GCCTAGCTAGCGTGTTCATCCCGTGCCTGTTACC } \\
\text { CCGGAATCTTCACATTGCTACTTGCAAAGCATTAAC } \\
\text { CGCGGATCCTCTCAAAAGGTTAGTGGAC } \\
\text { CGGAATTCCCTGAACTTTCCGTAGTCCTT } \\
\text { TAAAACTACTGATCGACAGAAGACAGTTGAA } \\
\text { TTCAACTGTCTTCTGTCGATCAGTAGTTTTA } \\
\text { GCGGAAGACAGTGGTGAACT } \\
\text { AGCTGGAGTAGTCGCTCTGC } \\
\text { CAGGAATCATCGGACTCAGG } \\
\text { GTTCACTTACACCAGCATCA } \\
\text { AGGGAAGAAACCCAAGAC } \\
\text { CATACTGGGCAGGGCTTA } \\
\text { CCCAAGCAATGGATGATTTGA } \\
\text { GGCATTCTGGGAGCTTCATCT } \\
\text { CACTGCCCAACAACACCAGCTCCT } \\
\text { GTCTGAGTCAGGCCCTTCTGTCTTG } \\
\text { TAACAGTTCCTGCATGGGCGGC } \\
\text { AGGACAGGCACAAACACGCACC } \\
\text { ACACGGCGACCCTACAAG } \\
\text { TTCTGCTGGATTCAACG } \\
\text { CTCAGTTCTCTCCCTTCC } \\
\text { CTCCCTACTCCTTTCCC } \\
\text { TTGATTAGCAGCGGAACAAGGAGT } \\
\text { TGGAGAACGGGACCAGGACAC } \\
\text { CGTGACATTAAGGAGAAGCTG } \\
\text { CTAGAAGCATTTGCGGTGGAC }\end{array}$ \\
\hline
\end{tabular}


small RNA was fractionated using an $8 \mathrm{M}$ urea denaturing $15 \%$ polyacrylamide gel, and the RNAs 18-26 nt in length were retrieved and purified. Two oligonucleotide adaptors were then ligated to the $5^{\prime}$ and $3^{\prime}$ ends of the retrieved RNA using T4 RNA ligase (Fermentas, Waltham, MA, USA). The following adaptor sequences were used: $5^{\prime}$ adaptor $5^{\prime}$-CTGTAGGCACCATCAAx-3' (x:DMT-0- C3-CPG) and $3^{\prime}$ adaptor $5^{\prime}$-ACTCGAGAAUUCCGAAA-3'. A cDNA library was generated by reverse transcription using M-MLV (Promega) with the primer $5^{\prime}$-TTGATGGTGCC TACAG- $3^{\prime}$ that was reversed complementary to the $5^{\prime}$ adaptor. The products were amplified using asymmetric PCR. After the lower-content primers were exhausted, the higher-content primers, which were labeled with Cy3 (for the control group) or Cy5 (for the experimental group), produced single-stranded DNA (ssDNA) samples. The following PCR primers were used: sense $5^{\prime}$-ACTCGAGAATTCCGAAA- $3^{\prime}$ and antisense $5^{\prime}-\mathrm{Cy} 3 /$ Cy5-CACTTGATGGTGCCTACAG- $3^{\prime}$. A $3 \times$ miRNA Hybridization Buffer (Ambion) was added to the PCR products. Following incubation at $95^{\circ} \mathrm{C}$ for $3 \mathrm{~min}$, the solution was added on the slide that contained 640 human mature miRNA-associated probes with each probe present in triplicate. Hybridization was carried out for $18-24 \mathrm{~h}$ at $42^{\circ} \mathrm{C}$, and the slide was washed and then scanned using the ScanArray Express microarray acquisition system of Packard Biochip Technologies (Waltham, MA, USA). All of the oligonucleotide sequences were purchased from Integrated DNA Technology (Coralville, IA, USA).

Cell cycle and apoptosis assays. Transfected cancer cells were seeded into six-well plates and incubated for $24 \mathrm{~h}$ in complete medium. Next, the cells were deprived of serum for $48 \mathrm{~h}$ and then returned to complete medium for an additional $24 \mathrm{~h}$. All cells were collected by centrifugation, fixed in $95 \%$ ethanol, incubated at $-20^{\circ} \mathrm{C}$ overnight and washed with phosphate-buffered saline (PBS). Then, the cells were resuspended in $1 \mathrm{ml}$ of FACS solution (PBS, $0.1 \%$ Triton $\mathrm{X}-100,60 \mu \mathrm{g} / \mathrm{ml}$ propidium iodide (PI), $0.1 \mathrm{mg} / \mathrm{ml}$ DNase free RNase and $0.1 \%$ trisodium citrate). After a final incubation on ice for $30 \mathrm{~min}$, the cells were analyzed using a FACS Calibur flow cytometer (Beckman Coulter, Brea, CA, USA). A total of 10000 events were counted for each sample.

For the TUNNEL assay, the cells were transfected with pcDNA3/pri-miR-509-5p or aso-miR-509-5p and were seeded into triplicate wells on a 14-well slide (Cell-Line/Erie Scientific Co., Portsmouth, NH, USA) at $48 \mathrm{~h}$ post transfection. Next, cell apoptosis was detected using the In situ Cell Death Detection Kit and Fluorescein (Roche Applied Science, Indianapolis, IN, USA) according to the manufacturer's instructions. DAPI staining was used to determine the number of nuclei and to assess the gross cellular morphology. For Annexin V assay, miR-509$5 p$ or Mdm2 expression plasmid was transfected into HeLa cells. After $48 \mathrm{~h}$, DNA content was determined by PI staining as described by Hwang et al., ${ }^{37}$ and Annexin $\mathrm{V}$ staining was performed with the Vybrant Apoptosis Assay Kit (Invitrogen).

Detection of p53 ubiquitination. Ubiquitination activity was determined using an in vitro ubiquitination assay. Cell extracts prepared from the transfected cells were immunoprecipitated with anti-p53 antibody. The presence of ubiquitin-conjugated p53 proteins in the immunoprecipitates was detected by immunoblotting with an anti-ubiquitin antibody.

Western blot analysis. Cells were lysed in RIPA buffer, and the lysates were analyzed using a standard western blot procedure. Glyceraldehyde-3phosphate dehydrogenase (GAPDH) was used as endogenous loading control. The following primary antibodies were used: polyclonal rabbit anti-human Mdm2, p53, p21 and bak (Saierbio, Tianjin, China).

ChIP assay. The ChIP assay was performed using EpiQuikTM Chromatin Immunoprecipitation Kit from Epigentek Group Inc. (Brooklyn, NY, USA). ProteinDNA complexes were immunoprecipitated with p53 antibody, a positive control antibody (RNA polymerase II), a negative control normal mouse IgG. GAPDH primers was used as a positive DNA sequence to demonstrate the efficacy of the kit reagents and protocol. RNA polymerase II is considered to be enriched in the GAPDH gene promoter that is expected to be undergoing transcription in most growing mammalian cells, and can be immunoprecipitated by RNA polymerase II, but not by normal mouse IgG. DNA from these samples was then subjected to PCR analysis. Primer sets for p53RE1 were miR509-P53site1-S: $5^{\prime}$-CTGTATTAG CCCATTTTC-3'; miR509-P53site1-AS: 5'-TTTGCCTGTCGCCATCC-3'; primer sets for p53RE2 were miR509-P53site2-S: 5'-CAAGTAGCAATGTGAAAAGG-3'; miR509-P53site2-AS: 5'-CTGCAGAATCCAATCCAC-3'.

Statistical analysis. Student's $t$-test was used to analyze the significance of the differences between sample means obtained from three independent experiments. The differences were considered statistically significant when ${ }^{*} P<0.05$.

\section{Conflict of Interest}

The authors declare no conflict of interest.

Acknowledgements. We thank Tianjin Medical University Cancer Institute and Hospital for providing the human cervical cancer tissue samples and the Cancer Center of Sun Yat-sen University of Medical Science for providing the human HCC tissue, as well as the College of Public Health of Tianjin Medical University for their technical assistance with the fluorescence detection. This work was supported by the National Natural Science Foundation of China (no: 31270818; 91029714; 31071191; 31101000; 31301132), the Natural Science Foundation of Tianjin (09JCZDJC17500; 12JCZDJC25100) and Foundation of Science \& Technology for University in Tianjin (no: 20120102).

1. Cech TR, Steitz JA. The noncoding RNA revolution-trashing old rules to forge new ones. Cell 2014; 157: 77-94.

2. Mendell JT, Olson EN. MicroRNAs in stress signaling and human disease. Cell 2012; 148 : 1172-1187.

3. Calin GA, Liu CG, Sevignani C, Ferracin M, Felli N, Dumitru CD et al. MicroRNA profiling reveals distinct signatures in B cell chronic lymphocytic leukemias. Proc Natl Acad Sci USA 2004; 101: 11755-11760.

4. Eades G, Yang M, Yao Y, Zhang Y, Zhou Q. miR-200a regulates Nrf2 activation by targeting Keap1 mRNA in breast cancer cells. J Biol Chem 286: 40725-40733.

5. Cho WC, Chow AS, Au JS. Restoration of tumour suppressor hsa-miR-145 inhibits cancer cell growth in lung adenocarcinoma patients with epidermal growth factor receptor mutation. Eur J Cancer 2009; 45: 2197-2206.

6. Yan Y, Luo YC, Wan HY, Wang J, Zhang PP, Liu M et al. MicroRNA-10a is involved in the metastatic process by regulating Eph tyrosine kinase receptor A4-mediated epithelialmesenchymal transition and adhesion in hepatoma cells. Hepatology 57: 667-677.

7. Chen L, Yang Q, Kong WQ, Liu T, Liu M, Li X et al. MicroRNA-181b targets cAMP responsive element binding protein 1 in gastric adenocarcinomas. IUBMB Life 64: 628-635.

8. Zhao $Y$, Samal E, Srivastava D. Serum response factor regulates a muscle-specific microRNA that targets Hand2 during cardiogenesis. Nature 2005; 436: 214-220.

9. Kong W, Yang H, He L, Zhao J-j, Coppola D, Dalton WS et al. MicroRNA-155 is regulated by the transforming growth factor $\beta / S$ mad pathway and contributes to epithelial cell plasticity by targeting RhoA. Mol Cell Biol 2008; 28: 6773-6784.

10. Merkel O, Asslaber D, Pinon J, Egle A, Greil R. Interdependent regulation of $p 53$ and miR-34a in chronic lymphocytic leukemia. Cell Cycle 2010; 9: 2836-2840.

11. Fernandez-Fernandez MR, Rutherford TJ, Fersht AR. Members of the $S 100$ family bind p53 in two distinct ways. Protein Sci 2008; 17: 1663-1670.

12. Hofmann TG, Möller A, Sirma H, Zentgraf H, Taya $Y$, Dröge $W$ et al. Regulation of p53 activity by its interaction with homeodomain-interacting protein kinase-2. Nat Cell Biol 2001; 4: 1-10.

13. Juan L-J, Shia W-J, Chen M-H, Yang W-M, Seto E, Lin Y-S et al. Histone deacetylases specifically down-regulate p53-dependent gene activation. J Biol Chem 2000; 275: 20436-20443.

14. Harris SL, Levine AJ. The p53 pathway: positive and negative feedback loops. Oncogene 2005; 24: 2899-2908.

15. Dubs-Poterszman MC, Tocque B, Wasylyk B. Mdm2 transformation in the absence of p53 and abrogation of the p107 G1 cell-cycle arrest. Oncogene 1995; 11: 2445-2449.

16. Peng Y, Chen L, Li C, Lu W, Agrawal S, Chen J. Stabilization of the Mdm2 oncoprotein by mutant p53. J Biol Chem 2001; 276: 6874-6878.

17. Wade M, Li YC, Matani AS, Braun SM, Milanesi F, Rodewald LW et al. Functional analysis and consequences of Mdm2 E3 ligase inhibition in human tumor cells. Oncogene 31: 4789-4797.

18. Bond GL, Hu W, Levine AJ. Mdm2 is a central node in the p53 pathway: 12 years and counting. Curr Cancer Drug Targets 2005; 5: 3-8.

19. Dar AA, Majid S, Rittsteuer C, de Semir D, Bezrookove V, Tong S et al. The role of miR-18b in Mdm2-p53 pathway signaling and melanoma progression. J Natl Cancer Inst 105: 433-442.

20. Chesi M, Bergsagel PL. Epigenetics and microRNAs combine to modulate the Mdm2/p53 axis in myeloma. Cancer Cell 18: 299-300.

21. Xiao J, Lin H, Luo X, Luo X, Wang Z. miR-605 joins p53 network to form a p53:miR605:Mdm2 positive feedback loop in response to stress. EMBO J 30: 5021.

22. Saha MN, Jiang H, Jayakar J, Reece D, Branch DR, Chang H. Mdm2 antagonist nutlin plus proteasome inhibitor velcade combination displays a synergistic anti-myeloma activity. Cancer Biol Ther 9: 936-944.

23. Love IM, Shi D, Grossman SR. p53 Ubiquitination and proteasomal degradation. Methods Mol Biol 962: 63-73. 
24. Aigner A. MicroRNAs (miRNAs) in cancer invasion and metastasis: therapeutic approaches based on metastasis-related miRNAs. J Mol Med (Berl) 89: 445-457.

25. Calin GA, Croce CM. MicroRNA signatures in human cancers. Nat Rev Cancer 2006; 6 857-866.

26. Hanlon K, Rudin CE, Harries LW. Investigating the targets of MIR-15a and MIR-16-1 in patients with chronic lymphocytic leukemia (CLL). PLoS One 2009; 4: e7169.

27. Wang CJ, Zhou ZG, Wang L, Yang L, Zhou B, Gu J et al. Clinicopathological significance of microRNA-31, -143 and -145 expression in colorectal cancer. Dis Markers 2009; 26 27-34

28. Zanesi N, Pekarsky Y, Trapasso F, Calin G, Croce CM. MicroRNAs in mouse models of lymphoid malignancies. J Nucleic Acids Investig 1: 36-40.

29. Calin GA, Sevignani C, Dumitru CD, Hyslop T, Noch E, Yendamuri S et al. Human microRNA genes are frequently located at fragile sites and genomic regions involved in cancers. Proc Natl Acad Sci USA 2004; 101: 2999-3004.

30. Zhang B, Pan X, Cobb GP, Anderson TA. microRNAs as oncogenes and tumor suppressors. Dev Biol 2007; 302: 1-12.

31. Waby JS, Chirakkal H, Yu C, Griffiths GJ, Benson RS, Bingle CD et al. Sp1 acetylation is associated with loss of DNA binding at promoters associated with cell cycle arrest and cell death in a colon cell line. Mol Cancer 9: 275

32. He L, He X, Lim LP, de Stanchina E, Xuan Z, Liang Y et al. A microRNA component of the p53 tumour suppressor network. Nature 2007; 447: 1130-1134.

33. Ba YH, Li HP. Advances in study of murine double minute 2/p53 passway with breas cancer. Beijing Da Xue Xue Bao 2006; 38: 551-554.
34. Chang C-J, Freeman DJ, Wu H. PTEN regulates Mdm2 expression through the P1 promoter. J Biol Chem 2004; 279: 29841-29848.

35. Héron-Milhavet L, LeRoith D. Insulin-like growth factor I induces Mdm2-dependent degradation of $\mathrm{p} 53$ via the p38 MAPK pathway in response to DNA damage. J Biol Chem 2002; 277: 15600-15606.

36. Xiao J, Lin H, Luo X, Luo X, Wang Z. miR-605 joins p53 network to form a p53: miR-605: Mdm2 positive feedback loop in response to stress. EMBO J 2011; 30: 524-532.

37. Hwang HW, Wentzel EA, Mendell JT 2007A hexanucleotide element directs microRNA nuclear import. Science 315: 97-100.

cc)(-) Cell Death and Disease is an open-access journal published by Nature Publishing Group. This work is licensed under a Creative Commons Attribution-NonCommercialShareAlike 3.0 Unported License. The images or other third party material in this article are included in the article's Creative Commons license, unless indicated otherwise in the credit line; if the material is not included under the Creative Commons license, users will need to obtain permission from the license holder to reproduce the material. To view a copy of this license, visit http://creativecommons.org/licenses/ by-nc-sa/3.0/

Supplementary Information accompanies this paper on Cell Death and Disease website (http://www.nature.com/cddis) 